\title{
General Treatment Principles in Alergies-Plastic Materials
}

\author{
AUREL NECHITA ${ }^{1}$, GETA MITREA ${ }^{1 *}$, GHEORGHE RAFTU2*, CRISTINA STEFANESCU ${ }^{1}$, DIANA MARIA ANTON ${ }^{1}$, GABRIELA POPA ${ }^{1}$, \\ LUANA ANDREEA MACOVEI ${ }^{3}$ \\ 'Dunarea de J os University of Galati, Medical Faculty, 47 Domneasca Str., 800008, Galati, Romania \\ 2 University Ovidius, Faculty of Dental Medecine, 124 Mamaia Blvd., 900527, Constana, Romania \\ ${ }^{3}$ Grigore T. Popa University of Medicine and Pharmacy lasi, Faculty of Medecine, 16 Universitatii Str., 700115, Iasi, Romania
}

\begin{abstract}
The occurrence and evolution of the disease depend on the properties of the organism, the cortical inhibition prevents the development of anaphylactic shock in humans. In some people, the increased and altered sensitivity manifests itself in the form of idiosyncrasy. In idiosyncrasy, the reactivity of the organism is altered from different substances of antigenic nature These substances can be food (milk, strawberries, eggs) or drug substances (iodine, iodoform, bromine, etc.) (drug idiosyncrasy whose symptoms are not related to the specific pharmacodynamic properties of the substance), plastics (prostheses, babies'dummy, etc.). The allergic reaction can be divided into two successive stages: a first stage of allergy, characterized by the formation of allergic type antibodies, their spread and fixation on certain tissues, and the second stage, of antigen -antibody, which represents the reaction In both stages there are both phases of immunological specificity (antibody production, antigen binding to the antibody) as well as non-specific phases in which the allergen and the antibody behave banal, non-immune (enter the body, circulate) or participate in reactions without immunological specificity (histamine release, etc.) The allergy therapy will appropriately include both specific methods and non-specific methods. Specific methods are only two: stopping the allergen input (allergen deficiency) and specific desensitization.Material and Method: $A$ sample of 183 patients was studied in the present study between 2013 and 2017 with suspicions of hypersensitivity to dental materials for local or general symptoms. Results and discussions: A more severe allergy can be manifested in the dental office, is caused by the local anesthetic. The dentist has several local anesthetics, and through a welldone questioning, he will decide which type of anesthesia is the one indicated. For these reasons, an allergic reaction to the anesthetic is less common, but its manifestations are rather severe if it does not intervene in time. Conclusions:Dental biomaterials, in addition to mechanical and chemical resistance, should not contain toxic diffusible elements in the general circulation, elements with allergic or carcinogenic potential.
\end{abstract}

Keywords: allergic reaction, production of antibodies, immunological specificity

LTT-dental plasric mass: TEGDMA, BISGMA, HEMA, Methylmetacrilate, diuretandimethyrylate, 4,4-izopropylidendifenol. Ethylene glycolimethylacrylate, $\mathrm{N}, \mathrm{N}$-dimethyl4-toluidine, benzoileroxide, hydro-chinone

The oral cavity as a first segment of the material importing device is permanently confronted with multiple allergenic substances, food, medication, hygiene products, dental materials and dental materials etc. However, allergic reactions at this level occur relatively rarely. However, when they appear to be either the local materialization of general immune conflicts or local contact reactions and a nonspecific clinical aspect[1-3].

The incidence of these reactions in practice is difficult to appreciate: due to their frequent passive, non-recurrent nature and without a very troublesome symptom, patients do not see the doctor. Even when the specialist is confronted with a non-specific clinical picture that can simulate a number of other inflammatory or dermatological conditions of the mucosa and the positive diagnosis remains uncertain. Sometimes only a careful follow-up of the patients or the repetitive character of the symptomatology eventually lead to a certainty of diagnosis.Today, allergy is a recognized problem, of pandemic proportions, affecting more than 150 million people in Europe alone. Taking into account the current evolutionary trend, the European Academy of Allergy and Clinical Immunology (EAACI) estimates that in 15 years more than half of the European population will suffer at least one type of allergy [4-6].
People susceptible to becoming allergic, more precisely atopic, synthesize a certain type of antibody ( $E$ immunoglobulins) in response to a narrower or wider range of environmental allergens. Some of these allergens are suspended in atmospheric air, which we commonly refer to as dust. Thus, the term allergy to dust has started and is widely used [ 7-10].

Approximately 45,000 different materials are used in dentistry today and it is estimated that 9,000 are included in the dental treatments themselves. The most important dental materials are: metals and alloys: Amalgame $(\mathrm{Hg}$, $\mathrm{Sn}, \mathrm{Cu}, \mathrm{Ag}$ ); Noble metals -EEM (Au, Pt, Ag, Pd); NEM alloys $(\mathrm{Co}, \mathrm{Cr}, \mathrm{Ni}, \mathrm{Fe})$; Alloys with a certain proportion of the mixture ( $\mathrm{Pd}, \mathrm{Ni}, \mathrm{Au}, \mathrm{Co}, \mathrm{Sn})$.

Dental ceramics (dental porcelain): used as such or blown on a metal support (Au, titanium). Combination of silicon, aluminum, alkaline or alkaline-earth metals and oxides. Dental plastics used in conservative dental medicine as composite materials and compomers for sealing cracks and as adhesives for enamel and dentin as well as in prosthesis for fixing crowns and bridges.

The composition comprises the organic component (matrix): acrylate (BisGMA, TEGDMA); inorganic filler material: quart, ceramic, oxide, fluoride; the binding phase between the filler material and the silane organic phase); catalyst system: benzoyl peroxide, amine, hydroquinoline, chemical stabilizers / inhibitors [11-13].

Materials for channel filling: gutta-percha cones; pastes for temporary or permanent fillings that may contain

\footnotetext{
*email: getamitrea@yahoo.com, Phone: 0744787999; gheorgheraftu@yahoo.com, Phone: 0722215626
} 
eugenol, zinc oxide, cadmium, aldehyde, epoxide, antibiotics, cortisone.

Metals and plastics contained in dental materials are potential allergens because soluble metal ions or monomers bind to albumin and may become haptens allergens to which the immune system reacts specifically. The highest allergenic power has nickel ions, but also gold, mercury, palladium, silver, cobalt, seldom platinum and rarely titanium. If there is an ordering of the metals after the awareness rate in the population, then nickel is first, with $15 \%$ for women (jewelry) and $6 \%$ for men, followed by gold with $3.5-9 \%$ (in the feminine population) and palladium by up to $5-8 \%$ in the general population. In contrast for mercury there are no gender differences, with $9.6 \%$ symptomatic clinical reactions to amalgam carriers. For other metals (platinum, silver, copper, iridium) the sensitization rate is below $1 \%$. In the case of plastics, there is little scientific research. However, there are indications that acrylate would be the main material responsible for sensitization. One should mention 2-hydroxy-ethyl-acrylate (12.1\% sensitization rate), 2-hydroxypropylmethacrylate (12.0\%) and 2-hydroxyethylmethacrylate (11.4\%)[14-16].

A number of studies were issued to evaluate the presence of allergy in people who have received dental implants. Thus, a study conducted in 2007-2010 evaluated the prevalence of titanium allergy; based on titanium, it was statistically significant in the subgroup of patients who developed allergic (or even failure) allergic manifestations after implantation.

Dental materials mainly cause type IV allergies with the production of numerous cytokines responsible for inflammatory phenomena. Only rare cases of type I hypersensitivity to mercury, plastics and non-metallic fill materials have been described. A sensitization can be evidenced by local or systemic symptoms.

Local signs are stomatitis, lichen ruber plan, gingivitis, periodontitis. Local symptoms include burns of the tongue, dental neuralgia, and mastication disorders.

General symptoms include headaches, migraines, neuralgia, myalgia, arthralgia, paraesthesia, fatigue, insomnia, and tendency to depression. To demonstrate sesibilization, the epicutan test is frequently used (patch test) based on the principle of a type IV hypersensitivity reaction.

It aims to induce an allergic inflammation on small skin surfaces (usually on the back) by applying a set of standard allergens contained in discs covered with hypoallergenic patches; the patches will be removed after 48 hours and the first reading of the test will be done by the dermatologist or allergologist specialist; in the case of a positive reaction, edema and sensitization erythema will be noted [17-9].

The final interpretation is done after another 48 hours to increase the chance of getting a positive result. The disadvantages of the test are that the assessment is subjective and the reproducibility of the weak positive reactions is questionable. The epicutan test does not reveal systemic sensitization, too. However, a clear positive test proves sensitization while a negative test does not exclude systemic sensitization.

An alternative to the patch test is the lymphoblastic transformation test (LTT), which measures the lymphocyte reactivity (proliferation) after exposure to allergens . LTT for metals, plastics and other materials used in dental medicine has been rigorously tested over the last eight years, optimized, and it is currently established that sensitization can be proven by objective measurements[2022].
A recent study, which included 700 patients, demonstrated that the optimized LTT test is a very useful tool for identifying people's awareness for symptoms with exposure to metals (including subjects with dental materials) [23-25].

Moreover, the test is also useful for monitoring because it was found that after constant exposure to the incriminated metals, lymphocyte reactivity normalizes (LTT becomes negative). For dental medicine, there are two types of tests (epicutan and LTT) to be observed not as alternatives, but as complementary methods to highlight sensitivities. For a preventive control is preferred LTT.

$L T T$ indications for dental materials are: suspicion of hypersensitivity to dental materials in case of local or general symptoms (curative purpose); exclusion of existing type IV hypersensitivity to metals or plastics in people with suggestive history (preventative purpose).

In the case of a proven sensitization, it is necessary to consider whether the material in question should be removed and replaced. The decisive factor is the severity of the symptomatology and in no case a positive isolated test. At the same time, other sources of exposure must be removed.

The inconclusive result occurs when the validation criteria for either positive control (lack of polyclonal activation of lymphocytes) or negative control (increased spontaneous proliferation) have been obtained. Given that the sampling and transport of the sample was performed under appropriate conditions, the lack of validation of the test may be due to prolonged immunosuppressive treatment, spontaneous proliferation due to immune system hyperactivity [26-28].

A positive result highlights the presence of an increased number of T cells with specific allergen memory, indicating lymphocyte sensitization and predisposition to allergic reactions, without necessarily leading to clinical manifestations. On the other hand, a negative result does not exclude sensitization to a dental material $[29,30]$.

\section{Experimental part}

\section{Materials and methods}

Allergy can be defined as an immunopathological phenomenon, characterized by a specific, exaggerated specific reactivity, acquired by sensitizing the body to a heterogeneous substance that causes the formation of specific antibodies, allergy is a state of exaggerated reactivity and pathological, because it occurs as a result of sensitization to different environmental antigens which, in the amount and frequency they are commonly encountered, are not harmful to the body; it is a reactivity gained from repeated sensitization contacts with a sensitizing antigen. Allergic reaction is specific, group allergic reactions or largely cross-sensitized to antigens having common antigenic structures with some triggering agents. The same can be said about reactions that occur apparently at first contact with the allergen.

In the present study, a sample of 183 patients was studied during the period 2013-2017, with suspicions of hypersensitivity to dental materials for local or general symptoms.

Oral mucosa and lips may be the site of allergic reactions integrated into a higher allergic manifestation (anaphylactic shock, or polysymptomatic allergies). lyolate mouth allergies have also been described. But the mouth is not only a simple organ of shock but also a source of allergen spreading: distant allergic manifestations (cutaneous, digestive, articular) with oral point of departure are also known. 


\section{Results and discussions}

Allergy is compared and sometimes confused with anaphylaxis. To specify the framework of these notions, it is necessary to make a parallel between them.

Anaphylaxis is a form of allergy, being an artificially challenged phenomenon, while allergy occurs in natural conditions. The period of anaphylactic sensitization is shorter than for allergic sensitization. In anaphylactic processes, desensitization is achieved more easily than in allergic ones.

Atthe basis of the anaphylactic and allergic sensitization phenomena lies the reaction between the antigen and the antibody. This triggers a series of complicated physiological processes that determine the humoral, histopathological and clinical characteristics of these manifestations.

Allergic reactions occur when the immune system misrepresents harmless substances. Antibodies generated by the immune defense response appear in known symptoms.

I. Allergic reactions in dentistry are type I anaphylactictype allergic reactions: angioedema, systemic anaphylactic stomatitis, contact stomatitis; orofacial granulomatosis; erythema of post-menopause, purpura, haemorrhagic allergic reactions; erythema multiforme, acute ulcerative rash, lichen planus.

II. Allergic contact (local) reactions: Plasmacite gingivitis / plasma glossitis, lichenoid / contact keratoses reactions. Clinical forms are the result of a general immune conflict with mouth and sometimes neighbouring regions. Varied clinique features, polymorphic that are based on both pathophysiological and non-immune mechanisms. Some of these may be framed in the large types of hypersensitivity reactions described by Gell and Coombs in 1975, although the possibility of association and different mechanisms is also excluded.

Symptoms of oral allergoses include (Chaput) mucous, neurological, glandular and articular signs. Unlike other allergic reactions, the objectification of subjective complaints can be very erratic, making diagnosis considerably more difficult. Mucosal allergic inflammation may range from erythema to ulceration, such as edema, vesicles, bubbles, aphtha, with single or multiple locations; at the level of lips that can write cheilite and licks.

Local neurological symptoms include various paraesthesia and sympathalgia. Glandular symptoms treat the suffering of the parotide, sublingual, submaxilateral or gingival labia mucosa: secretion disorders, edema, pain.

Symptoms of the joints concern the temporomandibular joint and are those of an arthritis. Allergic phenomena also occur during acute rheumatism. These occur due to the penetration of the body from a primary outbreak of their germs or toxins, and they are predominantly serous heart and joints. Primary outbreaks of rheumatic infection can be: oral cavity, nasopharyngeal (tonsils) dental granulomas.

Allergic manifestations of rheumatism are evidenced by the formation of granulomas in the heart and joints, which in their structure are similar to those found in rabbits, in case to provoke the Arthus phenomenon in the joints.

The allergens responsible for oral allergic manifestations are proprietary to oral or transit cavities (food, oral or sublingual medication).

Dental allergens are: substances used in obstructions (eugenol, zinc and copper oxide cement, formalin, paraffinic, amalgam, iodoform, timol, antibiotics, arsenic salts, ether).

Heavy metals can also allerg (mercury, gold, chromium and amalgam nickel) probably not as such but through the salts they form; materials used in prostheses: rubber, alloy resins; antibiotics, sulfamides, antiseptics, anesthetics, etc., other than those indicated above, used for obturations, substances used for oral hygiene, paste and tooth water/ mouthwash, the number of ingredients is very high (chlorophyll, formol, penicillin, carmin, oils, etc.) and allergen detection may be difficult, given the manufacturing secret; apical granulos. Diagnosis involves a careful history, a detailed objective exam, and tests. Tests should take into account that mucosal reactions evolve otherwise than on the skin, and that dental allergy may be of humoral or tissue type, especially prosthetic contact lesions.

As a general principle, testing should be performed on the oral mucosa itself; rubber suction cups or plates with small dimples/pits are used, the substance to be tested on the festoon or the suction cup, and then the device is applied to the oral mucosa.Spreng imagined for testing on certain areas of the mucosa a gold foil covering the various parts of the prosthesis (interposed between the prosthesis and the mucosa) or cover the various balls made in the prosthesis itself. After Spreng, testing should be done under the same mechanical conditions. The interruption of exposure to the allergen helps determine the diagnosis.

Treatment: Allergen removal is mandatory, allergens specific to dentistry are not suitable for specific desensitisation. The first therapeutic goal to be pursued is the detection and urgent elimination of the suspected allergen. If it is a medicine, it is good to have the suppression done with the consent of the treating physician to reevaluate the treatment.

Food allergens will be suppressed from the diet. Depending on the severity of the manifestations, the treatment can be done either in ambulatory or in hospital. In the case of less serious injuries, causative allergen suppression is the only treatment, and clinical evolution is the therapeutic trial. Patients should be advised to avoid caustic substances or incriminated foods. It is the case of fixed-drug erythema or anaphylactic stomatitis in limited forms. Skin patch testing is the only way to assess a person's sensitization to allergens used in dentistry. It is indicated as a screening method when we want to detect allergic risk before performing a dental work, as well as a diagnostic method for people who, after dental work, have had allergic or irritant allergic or dermatitis episodes or other allergic symptoms.

For an effective prevention and to avoid all the inconveniences and risks of dental allergies, we encourage patients to ask the doctor dentist details about the materials included in the planned dental work and their allergenic potential, and present themselves to the allergy testing cabinet whenever the above criteria are met.

\section{Conclusions}

As the first gateway to entry of matter into the body, the cavity oral is confronted with multiple allergenic substances, such as food, medicines, various hygiene products or even dental substances. Allergies in the sphere of the oral cavity are often of a transient character, do not have a precise symptom, and the patient does not appear to the doctor for this cause.

Allergic reactions are caused by the materials and substances used by the dentist. Latex gloves (a natural material) your doctor uses may cause an allergic reaction due to the patient's exposure to the glove latex glove. People who work in an environment where they are exposed to latex or those who have undergone many 
surgeries are more likely to have an allergic reaction to this material.

Allergological screening of dental materials is especially recommended for people who have ever had allergic episodes throughout life, but is useful to any patient who needs major and expensive dental care.

\section{References}

1.CLAUS-HERMANN BUCKENDORF, Umweltmedizinische Diagnostik zahnersat zinduzierter Schadigungen. In Umwelt Medizin Gesselschaft, 17(4), 2004.

2.ELIZABETH VALENTINE-THON, KURT MULLER, GIANPAOLO GUZZI, SYBILLE KREISEL, PETER OHNSORGE, MARTIN SANDKAMP. Neuroendocrinology Letters, 2006; 27 (Suppl.1):17-24.

3.HARALD RENZ et al. Allergo J 2010; 19:110-128.

4.SICILIA A, CUESTA S, COMA G, ARREGUI I, GUISASOLA C, RUIZ E. presentation at EAO, Zurich 2006.

5.POVARU S, TOVARU M, TRIFU P., Dermato-Venerologia, 47: 33-38/ 2002.

6.TOVARU S, TOVARU M, VULCAN P - Rev. Chir. Maxillo. Fac. Et Stomatologie, 2002.

7.W. NIEDERMEIER, B. MEYER,. Poster at Brisbane Convention \& Exhibition, Implant Prosthodontics \& Materials.

8.GRADINARU, I. , IGNAT ,L., DASCALU, C.G., SOROAGA, L.V., ANTOHE,M.E., Rev. Chim. (Bucharest), 69, no. 2, 2018, p.328-331

9.SOLOMON,S.,URSARESCU,I., MARTU,A., et.al., Rev. Chim. (Bucharest), 66, no. 8, 2015, p.1166-1168

10.SARBU,LG., LUNGU,N.C., FORNA,N.C.,et.al., Rev. Chim. (Bucharest), 64, no. 12, 2013, p.1404-1407

11.COSTAN,A.DIMA,A.,IONITA,I et al, Optoelectrinics and advanced materials-rapid co mmunications,5(1-2),2011, p.92-95

12.ZEGAN G., DASCALU CG, MAVRU R.B., Medical Surgical J ournal, 119(4),2015, pg.1153-1160

13.ANTOHE, M.E., DASCALU, C.,SAVIN, C., FORNA,N.C., BALAN, A., Mat. Plast., 53, no. 4, 2016, p. 767-770
14.TANCULESCU, O., DOLOCA, A., VIERIU,R.M et al., Rev. Chim.(Bucharest), 67, no. 1, 2016,p.96-102

15.MATEI,M.N., EARAR, K., TRINCA,L.C., Rev. Chim. (Bucharest), 67, no. 4, 2016, p.800-807

16.MARECI, D., EARAR, K., ZETU, I., et al., Mat. Plast., 52, no. 2,2015, p.150-153

17.ZEGAN, G, ANISTOROAIE, D., GOLOVCENCU , L., et al., Rev. Chim. (Bucharest), 68, no. 9, 2017, p.2052-2054

18.ANTOHE ME, FORNA AGOP D., DASCALU CG, Rev. Chim. (Bucharest), 69, no. 2, 2018 p.521-524

19.POPESCU, E., AGOP FORNA, D., EARAR, K., FORNA, N.C., Mat. Plast., 54, no.2, 2017, pg. 390-392

20.CHECHERITA, L., BELDIMAN, M.A., STAMATIN ,O., et al., Rev. Chim. (Bucharest), 64, no. 8, 2013, p.864-867

21. ZEGAN,G.,CARAUSU E., M, GOLOVCENCU,L., et al.Rev. Chim. (Bucharest), 68, no. 2,2017, p.2929-2931

22.J UMANCA,D., GALUSCAN,A.,PODARIU,A.C., et al.,Rev. Chim. (Bucharest), 65, no. 12, 2014 1473-1476

23.ASAFTEI,I.V., SANDU,I.G., BIRSA,L.M., et al.Rev. Chim. (Bucharest), 66, no. 3, 2015

24.LUNGU,M.,ROMILA, A., NECHITA,A., et.al., ACTA MEDICA MEDITERRANEA; 33(3), 2017, pg.369-376

25.GRIGORIU,R., CALIN,A.M., ARBUNE,M., et.al., Rev. Chim. (Bucharest), 67, no. 2, 2016, p.366-371

26.CALIN, A.D., ,PROCEEDINGS OF $201618^{\mathrm{TH}}$ INTERNATIONAL SYMPOSIUM ON SYMBOLIC AND NUMERIC ALGORITHMS FOR SCIENTIFIC COMPUTING(SYNASC), 2016, PG.264-261

27.SALARU,D.L., Mertens,P.R., BARTSCH, P, INTERNATIONAL UROLOGY AND NEPHROLOGY,45(5), 2013, PG.248-250

28.SALARU,D.L., MACOVEI, L., STATESCU, C., et al., REVISTA ROMANA DE MEDICINA DE LABORATOR, 21(4),2013, PG.407-414

29.COSTEA,C.F., TURLIUC,M.D., DIMITRIU, G., etal., Romanian J ournal of Morphology and embryology,58(3), 2017, pg.739-747

30.SCUTARIU,M.M., SALAMASTRAKIS,I., STAN,C.I., et al, Romanian J ournal of morphology and embryology, 57(3), 2016, pg. 1057-1061

Manuscript received: 6.12 .2018 